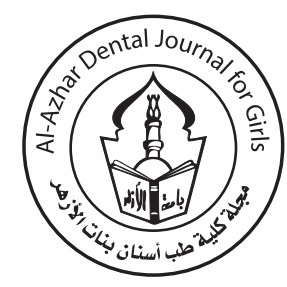

\title{
The Remineralizing Potential of Some Natural Materials Alone or Combined with Zamzam water on Demineralized Enamel
}

\author{
Reham Y. Abdo ${ }^{1 *}$, Maha A. Niazy ${ }^{2}$, Nevin A. Gad ${ }^{3}$
}

Codex : 04/21.01

azhardentj@azhar.edu.eg

http://adjg.journals.ekb.eg

DOI: 10.21608/adjg.2020.14199.1184

Restorative Dentistry

(Removable Prosthodontics, Fixed

Prosthodontics, Endodontics, Dental Biomaterials, Operative Dentistry)

\section{KEYWORDS}

Zamzam Water, Honey, Whey extract, Fluoride, Coca cola.

\begin{abstract}
Purpose: This study was designed to investigate the remineralizing potential of some natural materials (Honey, Whey extract, Zamzam water) versus synthetic product (fluoride tooth paste) on demineralized enamel. Materials and methods: A total of 40 premolars were extracted from 11-14 years old patients. Teeth were washed with distilled water to remove debris; and stored in distilled water contain $0.1 \% \mathrm{mg}$ thymol. Forty samples were sectioned into two parts (buccal and lingual) then divided into four main groups (20 each) according to materials used; A1: Ginger \& honey, A2:Whey extract, A3:Zamzam water \& ginger and A4:Fluoride tooth paste. The four groups were further subdivided into two subgroups according to the time of assessment; B1: after 20 days and B2: after 40 days. All samples were treated by demineralizing solution Coca-Cola for 8 minutes, then the samples were mounted and tested materials were applied. Samples were examined with polarized light microscopy. Results: After 20 days, the results revealed that the highest mean value of microhardness was recorded for ginger\& zamzam water (273.39), followed by whey extract (256.63), followed by Ginger \& honey groups (249.20) while Fluoride group showed the lowest mean of microhardness (219.56). This difference was statistically significant. After 40 days, the results revealed that the highest mean value of microhardness was recorded for Ginger \& Zamzam water (266.89), followed by Ginger \& honey (260.39), followed by Whey extract group (251.16) while Fluoride group showed the lowest mean of microhardness (226.44). This difference was statistically significant. Conclusion: Natural materials have remineralizing effect on enamel of tooth.
\end{abstract}

- Paper extracted from Master thesis titled 'The Remineralizing Potential of Some Natural Materials Alone or Combined With Zamzam water on Demineralized Enamel

1. Dentist at Ministry of Health, Egypt

2. Professor of Operative dentistry department, Faculty of Dental Medicine for Girls, Al-Azhar University, Cairo, Egypt.

3. Lecturer of Operative Dentistry, Faculty of Dental Medicine for Girls, AL-Azhar University, Cairo, Egypt.

* Corresponding author email: rehamyoussef7887@gmail.com 


\section{INTRODUCTION}

Currently dental erosion has been in the center of concern of many developed countries ${ }^{(1)}$. It was defined as incomplete demineralization of enamel or dentine as a result of chemical agents without involvement of microorganisms. Clinically dental erosion involves the destruction of tooth, leaving shiny surface and flattening of the convex surfaces. The consequences of dental erosion require its treatment ${ }^{(2)}$.

Opaque lesion is the first indication of tooth decay; which was defined as "subsurface enamel porosity from caries demineralization. This clinically revealed by a milky white opacity. Enamel destruction is permanent and does not restore ${ }^{(3)}$.

For caries prevention fluoride is considered as a confirmed agent; however too much use of fluoride cause fluorosis; and hardening of cartilage and hence the search for natural agent for enamel remineralizing was found worthiest ${ }^{(4)}$.

Ginger is natural herbal with antimicrobial activity. On the other hand, it does not display any toxicity and generally observed as safe by United States in the food and drug administration ${ }^{(5)}$.

More over nearly 4500 years the medicinal and antimicrobial effects of honey for wound healing have been innovate. A wide range of biological effects reveal by natural antioxidants and flavonoids involved anti-thrombotic, antiallergic, antibacterial, anti-inflammatory, and vasodilatory action. For periodontal cure, other oral infections, erosion of mucosa, and oral ulcers with no adverse response honey has ability to be useful ${ }^{(6,7) \text {. }}$

One of the essential dietary supplements is water. Zamzam water is drinking by millions of Muslims as sacred water. The water samples that examined by the European laboratories showed that $\mathrm{Za}$ mzam water has a special physical type that makes it beneficial water. The predominant difference that was found between city water and zamzam water in the amount of calcium and magnesium salts, the amount of these were somewhat higher in Zamzam water ${ }^{(8)}$.

Various studies were demonstrated that dairy products such as milk, cheese and yogurt which containing $\mathrm{CPP}-\mathrm{ACP}$ are effective in preventing dental caries ${ }^{(9)}$. The results of a study displayed that milk decreased the cariogenic potential of sugarcontaining foods.

During the process of cheese manufacturing whey is left over when milk is coagulated and has everything soluble from milk after $\mathrm{PH}$ dropping to 4.6 during the coagulation procedure. It is $5 \%$ of lactose solution in water with lactalbumin and few liquid contents.

\section{MATERIAL AND METHODS}

Forty premolars extracted from 11-14 years old patients for orthodontic treatment were used. The teeth were kept in distilled water and thymol at refrigerator $4 \mathrm{C}$ for a maximum period of one month until used ${ }^{(10)}$. Teeth were sectioned horizontally bellow cementoenamel junction to remove their roots then all teeth sectioned longitudinally from there occlusal surface into two parts (buccal and lingual) using a low speed double faced diamond disc (Besqual Dia-Disc NY 11373, USA size: $\mathrm{S}-22 \mathrm{~mm})$. Then buccal and lingual parts from the crown of all teeth were impeded from there pulpal surfaces on the acrylic blocks.

The eighty specimens were divided into four main groups (20 each) according to materials used for enamel surface treatment where A1: the enamel surface was treated by Ginger \& honey, A2: the enamel surface was treated by Whey extract, A3: the enamel surface was treated by Zamzam water \& ginger and A4: the enamel surface was treated by Fluoride tooth paste. Each group was further subdivided into two subgroups according to time B1: after 20 days and B2: after 40 days. In demineralizing solution the samples were saturated in $40 \mathrm{ml}$ of Coca-Cola for 8 minutes directly after opening the bottle cap ${ }^{(11)}$. 
The beverage was changed every 2 minutes (totally 4 times) to keep the gas and to decrease the buffering action of the ions which were dissolved from the enamel surface. Then the prepared materials were applied on the demineralized teeth enamel surfaces for all tested groups. Each material was applied on enamel surface of teeth about 10 minute every day for 20 days or 40 days then microhardness was measured.

\section{Storage of the specimens}

Each treated group was placed in separate container of distilled water at room temperature and the distilled water was replaced every day along the period of experiment.

\section{Microhardness assessment}

After 20 and 40 days microhardness values for all specimens were evaluated. Digital Display Vickers Micro-hardness Tester (Model HVS-50, Laizhou Huayin Testing Instrument Co., Ltd. China) with a Vickers diamond indenter and a 20X objective lens was used to detect surface microhardness of the specimens, where $200 \mathrm{gm}$ was applied to the specimens' surface for 20 seconds. Three indentations were made on the surface of each specimen. The indentations length was measured and Vickers values were converted into micro-hardness values.

\section{Polarized light microscopy assessment}

The specimens were observed under polarized Light microscope with Canada balsam as an imbibition medium. Photomicrographs were taken at X 100 magnification. The images were analyzed using image $\mathrm{J}$ software version. Longitudinal sections were cut and the images were captured and analyzed as described before to detect and compare the effect of tested materials.

\section{Statistical Analysis}

All the data were collected, tabulated and analyzed. One-way analysis of variance was performed, followed by a Tukey test when showed significance. Statistical analysis was performed; a value of $\mathrm{P}<$ 0.05 was recognized statistically significant.

\section{RESULTS}

\section{Microhardness}

Comparing the change of mean value of microhardness for each group after 20 days, the results revealed that Ginger \& Zamzam water group recorded statistically significant the highest mean value of microhardness $(273.39 \pm 18.08 \mathrm{HV})$, followed by whey extract group $(256.63 \pm 13.36 \mathrm{HV})$, followed by Ginger \& Honey (249.20 $\pm 27.83 \mathrm{HV})$ while Fluoride group showed significantly the lowest mean of microhardness $(219.56 \pm 22.47 \mathrm{HV})$. These different were statistically significant as indicated by one way ANOVA ( $\mathrm{F}=14.7, \mathrm{P}=0.0001<0.05)$.

Comparing the change of mean value of microhardness of each group after 40 days, ginger \& zamzam water recorded statistically significant the highest mean value of microhardness $(266.89 \pm 22.31 \mathrm{HV})$, followed by Ginger \& honey group $(260.39 \pm 19.22 \mathrm{HV})$, followed by Whey extract $(251.16 \pm 22.64 \mathrm{HV})$ while Fluoride group showed significantly the lowest mean of microhardness $(226.44 \pm 25.49 \mathrm{HV})$. This different was statistically significant as indicated by one way ANOVA $(\mathrm{F}=6.5, \mathrm{P}=0.0005<0.05)$.

Table (1) Vickers surface hardness (Mean $\pm S D$ ) values for enamel at 20 days and 40 days with different experimental groups.

\begin{tabular}{|c|c|c|c|c|c|}
\hline & \multirow{3}{*}{ Variables } & \multicolumn{4}{|c|}{ Treatment stage } \\
\hline & & \multicolumn{2}{|c|}{20 days } & \multicolumn{2}{|c|}{40 days } \\
\hline & & Mean & SD & Mean & SD \\
\hline \multirow{4}{*}{ 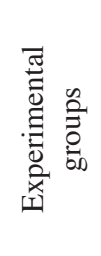 } & Fluoride & 219.56 & 22.47 & 226.44 & 25.49 \\
\hline & Whey & 256.63 & 13.36 & 251.16 & 22.64 \\
\hline & Ginger \& Zamzam & 273.39 & 18.08 & 266.89 & 22.31 \\
\hline & Ginger \& honey & 249.20 & 27.83 & 260.39 & 19.22 \\
\hline$P$ value & & \multicolumn{2}{|c|}{$0.0001 *$} & \multicolumn{2}{|c|}{$0.0005^{*}$} \\
\hline
\end{tabular}

* significant $(p<0.05)$ 


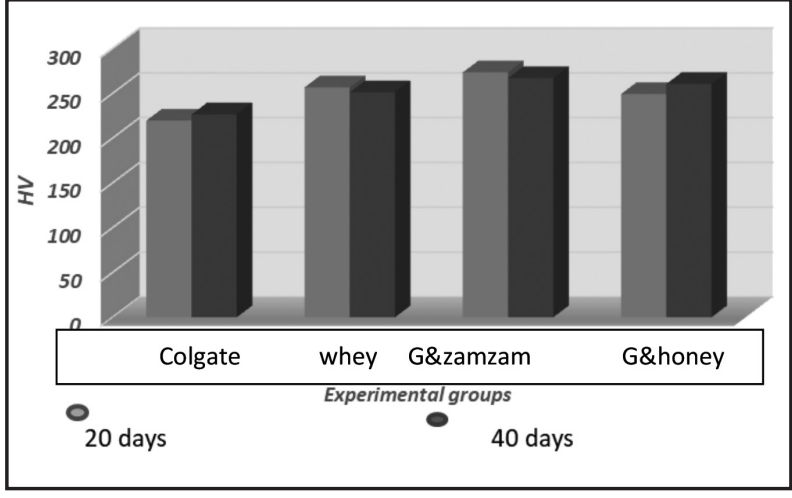

Figure (1) Column chart of the mean values of Vickers hardness for enamel at 20 days, and 40 days with different experimental groups

Comparing the change of mean value of microhardness for Ginger \& Zamzam water after 20 days and 40 days was statistically non-significant as indicated by one way ANOVA $(\mathrm{P}=0.4506<0.05)$ table (2).

\section{Polarized Light Microscope}

The demineralizing effect of coca cola was shown as dark area in figure (2A).

All tested group showed area of translucency on enamel surface. Mineral precipitation band was observed on the surface of enamel indicating remineralization of previous lesion for both experimental time (after 20 days \& 40 days).

Figures (2B) and (2C) showed the effect of Ginger \& honey mixture after periods of 20 and 40 days respectively. In both figures there is a translucent zone was observed on the surface of enamel which indicate remineralization of previous lesion and the area of translucency increased after 40 days.

Figures (2D) and (2E) showed the effect of Ginger \& Zamzam water mixture after periods of 20 and 40 days respectively. In both figures there is a translucent zone was observed on the surface of enamel which indicate remineralization of previous lesion but with a quite decreasing in the translucency after 40 days.
Table (2) Vickers surface hardness (Mean $\pm S D$ ) values for enamel at 20 days and 40 days with Ginger \& Zamzam water experimental group

\begin{tabular}{|c|l|c|c|c|c|}
\hline \multirow{2}{*}{\multicolumn{2}{|c|}{ Variables }} & \multicolumn{4}{c|}{ Treatment stage } \\
\cline { 2 - 6 } \multicolumn{2}{|c|}{} & \multicolumn{2}{|c|}{20 Days } & \multicolumn{2}{c|}{ 40 Days } \\
\cline { 3 - 6 } & Mean & SD & Mean & SD \\
\hline $\begin{array}{c}\text { Experimental } \\
\text { group }\end{array}$ & $\begin{array}{c}\text { Ginger \& } \\
\text { Zamzam }\end{array}$ & 273.39 & 18.08 & 266.89 & 22.31 \\
\hline ANOVA & P value & \multicolumn{4}{|c|}{$0.4506 \mathrm{~ns}$} \\
\hline
\end{tabular}

Comparing the change of mean value of microhardness for fluoride after 20 days and 40 days was statistically non significant as indicated by one way ANOVA ( $\mathrm{P}=0.6267>0.05)$ table (3).

Table (3) Vickers surface hardness (Mean $\pm S D$ ) values for enamel at20 days, and 40 days with Fluoride experimental group

\begin{tabular}{|c|c|c|c|c|c|}
\hline \multirow{3}{*}{\multicolumn{2}{|c|}{ Variables }} & \multicolumn{4}{|c|}{ Treatment stage } \\
\hline & & \multicolumn{2}{|c|}{20 Days } & \multicolumn{2}{|c|}{40 Days } \\
\hline & & Mean & SD & Mean & SD \\
\hline $\begin{array}{l}\text { Experimental } \\
\text { group }\end{array}$ & Fluoride & 219.56 & 22.47 & 226.44 & 25.49 \\
\hline ANOVA & $\mathrm{P}$ value & \multicolumn{4}{|c|}{$0.6267 \mathrm{~ns}$} \\
\hline
\end{tabular}

Figures (2F) and (2G) showed the effect of Whey extract after a period of 20 and 40 days respectively In both figures there is a translucent zone was observed on the surface of enamel which indicate remineralization of previous lesion with a quite decreasing in the translucency after 40 days.

Figures $(2 \mathrm{H})$ and (2I) showed the effect of Flouride after periods of 20 and 40 days respectively. In both figures there is a translucent zone was observed on the surface of enamel which indicate remineralization of previous lesion and the area of translucency increased after 40 days. 


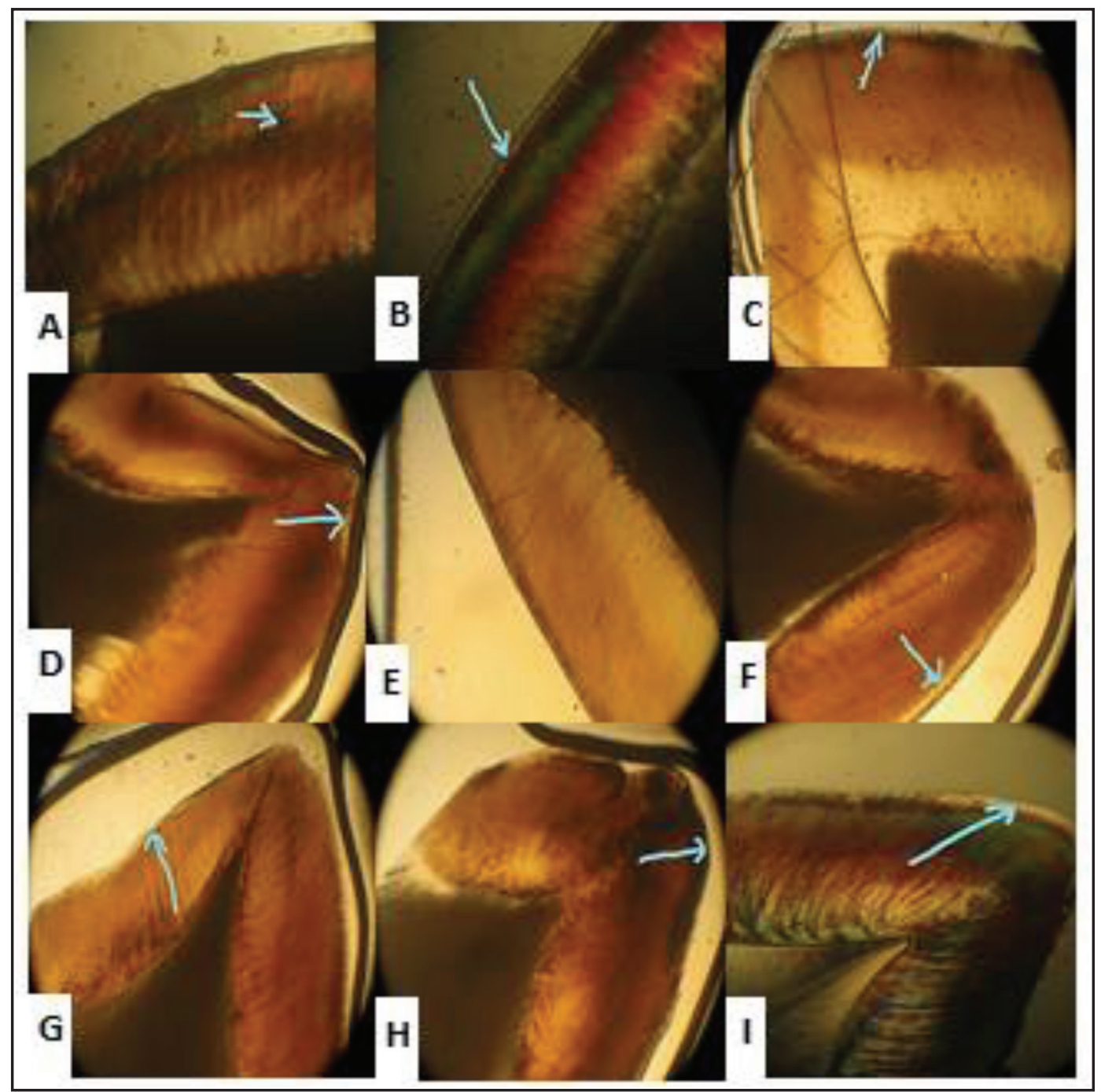

Figure (2): Polarized light microscope (2A) demineralized enamel, (2B) G\&H 20days, (2C) G\&H 40 days, (2D) G\&Z 20days, (2E) G\&Z 40 days, (2F) Whey 20 days, (2G) Whey 40 days, (2H) Fluoride 20 days and (I) Fluoride 40 days.

\section{DISCUSSION}

This study was evaluated the remineralizing effect of some natural materials (Ginger \& Zamzam water, Ginger \& honey and Whey) versus synthetic product (fluoride tooth paste).

The hard dental tissue are regularly undergoing cycles of demineralization and remineralization. The progression of dental caries occurred when the demineralization exceeds remineralization ${ }^{(12)}$.

Re-mineralization is a procedure whereby calcium and phosphate ions are supplied from an external source to tooth enamel ${ }^{(13)}$. Developing countries need biocompatible and cost effective preventive methods due to their financial situations. There for instead of using artificial materials, it has been proposed to use medical plant extract \& natural materials which play a role against causative bacteria of tooth decay ${ }^{(14)}$. In the present study the samples were immersed in a demineralizing solution for 8 minutes, to inducing an early enamel lesion, each material was applied on enamel surface of teeth about 10 minute every day for 20 days or 40 days then microhardness was measured ${ }^{(15,16)}$. 
Microhardness measurement was chosen in this study as it is appropriate for material having fine microstructure, nonhomogeneous and prone to cracking like enamel ${ }^{(12)}$. There were two stages of measurement of microhardness in this study after 20 and 40 days. Polarized light microscopic analysis was also used in this study because it is considered very sensitive procedure demonstrating changes of dental tissues and it has been widely used in studies of de/remineralization of teeth for a long time ${ }^{(17)}$. This technique allows differentiating between sound and demineralized substrates by differences in the tissues birefringence ${ }^{(18)}$.

In this study the Ginger \& Zamzam water group was recorded the highest mean value of microhardness after 20 and 40 days compared with other groups. This may be due to integration of Zamzam water elements (fluoride, calcium, and magnesium) with appetite crystals which developing the resistance to acid dissolution ${ }^{(19)}$. This result was in disagreement with another study which compares the effect of Zamzam water alone with CPP-ACPF and found that CPP-ACPF had remineralizing effect higher than zamzam water, this may be due to incorporation of fluoride with $\mathrm{CPP}-\mathrm{ACP}{ }^{(6)}$.

Another promising remineralizing agent used in this study was whey extract. It was recorded the highest mean value of microhardness after Ginger \& Zamzam water group, this could be due to high amount of $\mathrm{Ca}$ and $\mathrm{p}$ ions and the content of casein phosphopeptides (CPPs) ${ }^{(20)}$. Dairy products may diminish enamel demineralization by several mechanisms. Levine suggested three mechanisms; Firstly, the enamel surface may adsorbed by milk proteins which may impede enamel demineralization, secondly, the enamel surface may be adsorbed by milk fats which may have a protective effect and thirdly, reducing the growth of acidogenic plaque bacteria may be due to the role of milk enzymes ${ }^{(21)}$.
In this study a mixture of Ginger \& honey was effective as a remineralizing agent. This may be due to high fluoride content of ginger ${ }^{(10)}$, or may be that honey includes factors that may decrease the solubility of exposed enamel in acid buffer solution ${ }^{(22)}$. Another study reported that the effective remineralizing role of ginger \& honey mixture could not distinguished whether it resulted from ginger due to fluoride content, but it seems that there might be some enhancing effect on initial lesions. However, honey may activate releasing fluoride from ginger at the time of application resulting in higher remineralization ${ }^{(23)}$. This study was in agreement with another study which compared the effect of Ginger and honey with another natural material and fluoride tooth paste and reported that ginger and honey had remineralizing effect higher than fluoride tooth paste $^{(3)}$.

Even though colgate tooth paste had much more fluoride $(1,450 \mathrm{ppm})$, it has provided less remineralization than other groups.

Polarized light microscope observations of the present study correlates well with the microhardness results, where with a demineralizing material it was showed dark area due to lose of minerals and penetration of a demineralizing material through enamel surface. With tested materials enamel surface showed area of translucency with variations according to tested materials. This translucent zone knows as mineral percipetation band was observed on the surface of enamel representing remineralization of previous lesion ${ }^{(24)}$.

\section{CONCLUSION}

Natural materials have remineralizing effect on enamel of tooth. Though Ginger \& Zamzam water was an efficient as a remineralizing agent. Natural materials could successfully replace the synthetic products. 


\section{REFERENCES}

1. Tantbirojn D, Huang A, Ericson MD, Poolthong S. Change in surface hardness of enamel by a cola drink and a CPPACP paste. J Dent. 2008; 36: 74-9.

2. Huysmans MC, Chew HP, Ellwood RP. Clinical studies of dental erosion and erosive wearCaries. Res. 2011; 45: $60-8$.

3. Mount GJ. Anew paradigm for operative dentistry. J Conserve Dent 2008; 11:3-10.

4. Kaminsky LS, Mahoney MC, leach J, Melius J, Miller MJ. Fluoride: benefits and risks of exposure. Crit Rev Oral Biol Med 1990; 1: $261-81$.

5. Ohara A; Saito F; Matsuhisa T. screening of antibacterial activities of edible plants against Streptococcus mutans. Food Sci Technol Res 2008; 14:190-3

6. Molan PC. Honey for treatment of infections. The New Zealand Beekeeper 216: 1920.

7. Iurlina MO, Fritz R. Characterization of microorganisms in Argentinean honeys from different sources. Int J Food Microbiol. 2005; 105: 297-304.

8. Analytical report of Zamzam water cited from the ministry of agriculture and water resources (personal communication) 1971.

9. Thompson A, Grant LP, Tanzer JM. Model for assessment of carious lesion remineralization, and remineralization by a novel toothpaste. J Clin Dent. 1999; 10: 34-9.

10. Athraa' M. Al-Weheb, Ali Hadi Fahad. Effect of Zamzam water on the microhardness of initial caries-like lesion of permanent teeth, compared to Casein PhosphopeptideAmorphous Calcium Phosphate agents. J Bagh College Dent. 2012; 24: 28-132.

11. Rezvani MB., Karimi M., Akhavan Rasoolzade R., Haghgoo R. Comparing the Effects of Whey Extract and Casein Phosphopeptide-Amorphous Calcium Phosphate (CPP-ACP) on Enamel Microhardness. J Dent Shiraz Univ Med Sci. 2015; 16: 49-53.

12. Nagarathana C, Sakunthala BK, and Naveena Preethi P. An Update on Current Remineralizing Agent. OHDM 2015; 14: 183-7.
13. Kamh RA. Clinical Performance and Remineralization Potential of Different Biomimitic Materials. AD J 2018; 5: 349-58.

14. Gulcin BG., Funda Yg. Effectiveness of some herbals on initial enamel caries lesion. Asian Pac J Trop Biomed 2016; 6: 846-50.

15. Rezvani MB., Karimi M., Akhavan R., Haghgoo R. Comparing the Effects of Whey Extract and Casein Phosphopeptide-Amorphous Calcium Phosphate (CPPACP) on Enamel Microhardness. J Dent Shiraz Univ Med Sci. 2015; 16: 49-53.

16. Rahul R., Ashish Jain. Comparative evaluation of remineralizing potential of Fluoride using three different remineralizing protocols: An in vitro study. J Conserv Dent 2017; 20: 463-66.

17. Arends J; Ten Bosch J.J. Demineralization and remineralization evaluation techniques. J D S1992; 71: 924-8.

18. Lo E.C, Zhi Q.H, Itthagarun A. Comparing two quantitative methods for studying remineralization of artificial caries. J of dentistry 2010; 38: 352-9.

19. Al-Rawi N, Al-Alousi J, Al-Obaidy N. Effect of Zamzam water on the microhardness of initial carious lesion of permanent teeth enamel. M D J 2009; 6: 110-6.

20. McDougall WA. Effect of milk on enamel demineralization and remineralization in vitro. Caries Res 1977;11:166-72.

21. Ferrazzano GF., T Cantile. Protective effect of yogurt extract on dental enamel demineralization in vitro. Austr. D J 2008; 53: 314-9.

22. Sela M.O, Shapira L, Grizim I. Efects of honey consumption on enamel microhardness in normal versus xerostomic patients. J Oral Rehabil 1998; 25: 630-4.

23. Bilgin G, Yanikglu F, Tagtekin D. Remineralization potential of herbal mixtures; An in-situ study. Ind J Res 2016; 5: $145-9$.

24. Rajan R, Krishnan R, Bhaskaran B, Kumar SV. A Polarized Light Microscopic Study to Comparatively evaluate Four Remineralizing Agents on Enamel viz CPP-ACPF, ReminPro, SHY-NM and Colgate Strong Teeth. Int J Clin Pediatr Dent. 2015; 8: 42-7. 